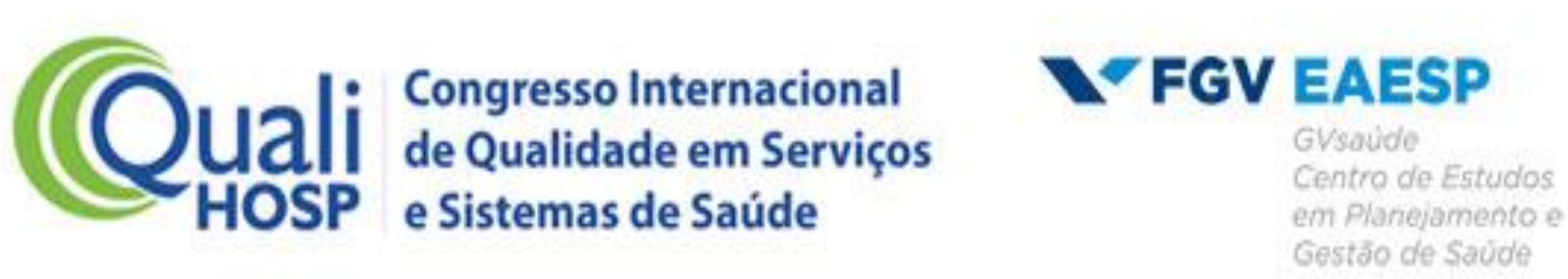

Ana Conceição de Lima Andrade Patrícia do Prado Costa Braga, Roseli Gomes Cavalini, Sheila Pereira Mendes, Sheila Roberto Nascimento

\title{
A EFETIVIDADE NA REALIZAÇÃO DA GESTÃO DO PLANO DE CUIDADOS A PACIENTES ONCOLÓGICOS EM HOSPITAL DA REDE PUBLICA DO MUNICIPIO DE MOGI DAS CRUZES
}

Eixo temático: Gestão em Saúde

INTRODUÇÃO: 0 enfermeiro como gerenciador do cuidado, deve ter uma visão holística voltada para o paciente diante de suas necessidades apresentadas, bem como ser reconhecedor de possíveis complicações, voltadas não só para as necessidades humanas básicas, mas também para as necessidades de cuidados específicos. A elaboração de um plano de cuidados possibilita uma atuação pontual e assertiva diante desses fatores.

JUSTIFICATIVA: O enfermeiro como parte da equipe de saúde tem papel fundamental no processo de cuidado a esses pacientes oncológicos em vigência de quimioterapia com medidas preventivas e ações efetivas proporcionando assim uma boa qualidade de vida.

OBJETIVO: Avaliar as ações de enfermagem desenvolvidas pelo enfermeiro por meio da prescrição de enfermagem para prevenir as complicações relacionadas ao tratamento em um Centro Oncológico.

MÉTODO: Trata-se de uma pesquisa de abordagem qualitativa do tipo descritivoexploratória, realizado em centro oncológico, localizado no município da grande São Paulo.
RESULTADOS: O plano assistencial foi elaborado com base nos diagnósticos de enfermagem levantados no NANDA, com as prescrições seguindo as determinações do NIC e NOC. Esse estudo elaborou um plano de cuidados com base nos diagnósticos de enfermagem, associando-os às possíveis complicações atreladas a essa injúria, na tabela 1 podemos evidenciar o resultado encontrado após a sua implantação. Com isso, foi estabelecido um plano que teve como visão a prevenção das possíveis complicações.

Tabela 1 : Descrição dos resultados evidenciados, após a implantação do plano de cuidados de enfermagem em pacientes sob vigência de quimioterapia em centro oncologico, Mogi das Cruzes, 2018.

\begin{tabular}{lcc}
\hline Cuidados para evitar complicaçóes & N $^{*}$ & $\begin{array}{c}\text { Percentual } \\
(\%)\end{array}$ \\
\hline Estado emocional equilibrado & 8 & $80 \%$ \\
Melhor adesão ao tratamento & 3 & $30 \%$ \\
Promoção da qualidade de vida & 4 & $40 \%$ \\
Redução das reações adversas & 4 & $40 \%$
\end{tabular}

CONCLUSÃO: O estudo possibilitou evidenciar que os enfermeiros tem conhecimento no plano de cuidado a pacientes oncológicos onde contribui no planejamento e implementação do cuidado, proporcionando melhorias na assistência prestada, possibilitando assim qualidade, conforto e segurança ao paciente em vigência de quimioterapia. 